\title{
PENGARUH KOREKSI BIAS IONOSFER TERHADAP HASIL KOORDINAT PENGAMATAN GPS SINGLE FREQUENCY MENGGUNAKAN MODEL KLOBUCHAR
}

\author{
Ririn Wuri Rahayu*1, Mokhamad Nur Cahyadi ${ }^{2}$, Buldan Muslim ${ }^{3}$ \\ ${ }^{1,2}$ Department of Geomatics Engineering, FTSLK-ITS, Kampus ITS Sukolilo, Surabaya, 60111, Indonesia \\ ${ }^{3}$ Space Science Center, LAPAN, Jl. Dr. Junjunan 133 Bandung, Indonesia \\ e-mail: 1 ririn14@mhs.geodesy.its.ac.id
}

\begin{abstract}
Abstrak
Sinyal satelit GPS dipengaruhi oleh beberapa jenis faktor kesalahan, di antaranya penundaan sinyal GPS oleh ionosfer. Pada GPS single frequency bias ini dapat dikoreksi menggunakan Model Klobuchar, yang memperkirakan penundaan waktu ionosfer hingga 50\% atau lebih. Untuk menggunakan model Klobuchar membutuhkan delapan koefisien Klobuchar $(\alpha n, \beta n$, untuk $n=1,2,3,4$ ) dan disediakan melalui pesan navigasi. Koefisien Klobuchar didapatkan dari perhitungan data pengamatan GPS yang terdistribusi di seluruh dunia dengan metode yang tidak terpublikasi. Dalam penelitian ini, satu set koefisien Klobuchar dihitung menggunakan data pengamatan GPS lokal sehari sebelumnya dan digunakan sebagai parameter navigasi pada hari selanjutnya untuk menentukan koordinat titik pengamat. Penelitian ini menggunakan perangkat lunak RTKLIB untuk mengolah hasil koordinat. Hasil penelitian ini didapatkan nilai koordinat meningkat sebesar 26,015\% dengan menggunakan koefisien lokal.
\end{abstract}

Kata kunci : Bias lonosfer, GPS Single Frequency, Model Klobuchar, RTKLIB

\section{PENDAHULUAN}

Bias ionosfer terjadi ketika sinyal GPS dibiaskan oleh elektron bebas di ionosfer, dan jumlah kesalahan yang dihasilkan oleh bias ionosfer bergantung pada lokasi pengamat, waktu, dan aktivitas matahari. Bias ionosfer terjadi dalam ukuran sentimeter sampai meter selama aktivitas matahari sedang, namun dapat terjadi hingga lebih dari $150 \mathrm{~m}$ selama aktivitas matahari yang parah (Komjathy dkk. 2002). Pada Mei 2000, pemerintah Amerika mengumumkan bahwa kesalahan akibat bias ionosfer dianggap sebagai faktor kesalahan terbesar yang mempengaruhi akurasi posisi GPS. Karena bias ionosfer mengakibatkan penurunan akurasi GPS pada Standard Positioning Service (Yuan dkk. 2007).

Untuk menghilangkan kesalahan akibat bias ionosfer, perlu dilakukan koreksi bias ionosfer. GPS dual frequency yang menerima frekuensi L1 dan L2 dapat menghilangkan sebagian besar kesalahan ionosfer melalui kombinasi bebas ionosfer. Namun, biaya penggunaan GPS dual frequency relatif mahal, dan karena itu jika penentuan posisi tidak memerlukan akurasi observasi dalam satuan milimeter hingga centimeter, GPS single frequency umumnya digunakan. Tetapi, karena GPS single frequency hanya menerima satu frekuensi (L1), maka kombinasi bebas ionosfer tidak dapat digunakan dalam pengolahan data GPS single frequency.

Sampai saat ini, untuk mereduksi kesalahan bias ionosfer pada GPS single frequency umumnya menggunakan pendekatan model atau alogaritma. Diantaranya, model Klobuchar, Bent, IRI, ICED dan FAIM. Model Klobuchar adalah model yang paling banyak digunakan, karena strukturnya sederhana dan perhitungannya mudah (Yuan dkk. 2008). Untuk menggunakan model Klobuchar, diperlukan delapan koefisien Klobuchar, an, $\beta n(n=1,2,3,4)$ yang terdapat pada Broadcast Messages. Menurut Schaer (2003) dalam Yuan (2008), Pusat Penentuan Orbit di Eropa (CODE) memberikan serangkaian waktu model koefisien Klobuchar, yang didapat dari penggabungkan data pengamatan GPS IGS terdistribusi di seluruh dunia dengan metode yang tidak dipublikasikan. Penelitian Hernandez pada tahun 2003 menunjukkan bahwa kombinasi data pengamatan GPS dari banyak stasiun pengamatan internasional GNSS (IGS) yang disebarkan secara global dan beberapa stasiun GPS jaringan regional. Hal tersebut yang mendasari penelitian Yuan (2008) untuk mempelajari koefisien Klobuchar dan 
mengembangkan sebuah metode untuk meningkatkan akurasi model Klobuchar.

Berdasarkan hasil penelitian Yuan (2008), didapatkan kesimpulan bahwa akurasi posisi pengamatan GPS single frequency dapat meningkat dengan menggunakan koefisien yang telah dikembangkan menggunakan model Klobuchar. Penelitian ini terinspirasi dari penelitian Yuan (2008), dengan menggunakan metode yang telah dikembangkan dalam penelitian tersebut. Penelitian ini akan melakukan perhitungan koefisien Klobuchar dengan menggunakan data pengamatan GPS geodetik lokal, koefisien hasil perhitungan akan disebut sebagai Koefisien Klobuchar lokal dan koefisien dari Broadcast Messages akan disebut sebagai Koefisien Klobuchar global. Kemudian melakukan perhitungan posisi koordinat pada titik pengamatan GPS single frequency menggunakan RTKLIB dan perubahan akurasi yang dihasilkan koefisien Klobuchar lokal.

\section{METODE}

\section{Lokasi Penelitian}

Lokasi penelitian ini adalah di titik Benchmark Departemen Teknik Geomatika ITS dan titik Benchmark Rektorat ITS dengan koordinat geografis $7^{\circ} 16^{\prime} 47,46^{\prime \prime} \mathrm{LS}-112^{\circ} 47^{\prime} 42^{\prime \prime}$ BT dan $7^{\circ}$ $16^{\prime} 55,2^{\prime \prime}$ LS - $112^{\circ} 47^{\prime} 39^{\prime \prime}$ BT. dengan menggunakan program fortan rdeph.f dengan interpolasi data setiap 30 detik.

b. Perhitungan sudut elevasi, Azimuth dan koordinat IPP satelit.

$r_{s}=\sin \phi \cos \theta r_{x}+\sin \phi \sin \theta r_{y}-\cos \phi r_{z}$

$r_{E}=-\sin \theta r_{x}+\cos \theta r_{y}$

$r_{z}=\cos \phi \cos \theta r_{x}+\cos \phi \sin \theta r_{y}+\sin \phi r_{z}$

$$
r=\mathrm{V}\left[r_{S}^{2}+r_{E}^{2}+r_{Z}^{2}\right]
$$

$\mathrm{E}=\sin ^{-1}\left(r_{z} / r\right)$

$\mathrm{Az}=\tan ^{-1}\left(-r_{E} / r_{S}\right)$

Keterangan:

$r_{S}, r_{E}, r_{Z} \quad \begin{aligned} & =\text { jarak vektor koordinat satelit dan } \\ & \text { pengamat }\end{aligned}$

$\phi, \theta=$ Koordinat pengamat

EI = sudut elevasi

$\mathrm{Az} \quad=$ Sudut Azimut

c. Perhitungan Bias ionosfer (Tiono)

Parameter yang digunakan untuk menghitung bias ionosfer adalah:

(i) Koordinat posisi satelit $(X, Y, Z)$

(ii) Koefisien Klobuchar pada file rinex navigasi

(iii)Lintang geomagnetik pada ionospheric pierce point dihitung dengan menggunakan rumus berikut:

$$
\varphi_{m}=\varphi_{i}+0,064 \cos \left(\lambda_{i}-1.167\right)
$$

\section{Permodelan Klobuchar lokal}

a. Perhitungan nilai koordinat satelit dari data Navigasi, pada tahap ini dilakukan dimana $\varphi_{i}$ dan $\lambda_{i}$ adalah lintang dan bujur pada ionospheric pierce point. Koefisien Klobuchar merupakan 8 buah nilai yang disebut koefisien ion 
alpha $\left(\alpha_{0}, \alpha_{1}, \alpha_{2}, \alpha_{3}\right)$ dan ion beta $\left(\beta_{0}, \beta_{1}, \beta_{2}, \beta_{3}\right)$ pada Broadcast Message. Koefisien ion alpha digunakan untuk menghitung amplitudo (AMP) dan Koefisien ion beta digunakan untuk menghitung periode (PER), dengan rumus:

$$
\begin{gathered}
A M P=\sum_{n=0}^{3} \alpha_{n} \varphi_{m}^{n} \\
\text { (8) } \\
\text { PER }=\sum_{n=0}^{3} \beta_{n} \varphi_{m}^{n}
\end{gathered}
$$

dimana $\varphi_{m}$ adalah lintang geomagnetik. Selanjutnya nilai AMP dan PER digunakan untuk menghitung nilai bias ionosfer (Tiono), dimana menggunakan persamaan berikut:

$$
T_{\text {iono }}=\left\{\begin{array}{ll}
F *\left[D C+A M P \cdot\left(1-\frac{x^{2}}{2}+\frac{x^{4}}{24}\right)\right] & ,|x|<1.57 \\
F * D C & ,|x| \geq 1.57
\end{array}\right\}(s)
$$

Dengan $D C$ adalah konstanta delay waktu vertikal pada malam hari $\left(5 \mathrm{~ns}=5 \times 10^{9} \mathrm{~s}\right)$, dan $F$ adalah faktor kemiringan proyeksi yang didapat dengan persamaan:

$$
F=1,0+16,0(0,53-E I)^{3}
$$

\section{d. Linearisasi model Klobuchar}

Pada tahap ini dilakukan penyusunan persamaan linearisasi untuk mendapatkan koefisien $\alpha_{n}$ dan $\beta_{n}$. Dimana pada tahap sebelumnya nilai koefisien Klobuchar dari file rinex navigasi dianggab sebagai initial value. Persamaan linearisasi yang digunakan mengadopsi dari paper Klobuchar 2008, persamaan tersebut dituliskan sebagai berikut:

$$
T_{\text {iono }}=T_{\text {iono }}^{0}+\sum_{n=0}^{3} \frac{\partial T_{\text {iono }}}{\partial \alpha_{n}} \cdot d \alpha_{n}+\sum_{n=0}^{3} \frac{\partial T_{\text {iono }}}{\partial \beta_{n}} \cdot d \beta
$$

Persamaan diatas digunakan untuk menyusun matrik A (Matrik Jacobian) sebagai berikut:

$$
\left[\begin{array}{cccccc}
\frac{\partial T_{\text {iono }}^{1}}{\partial \alpha_{0}} & \cdots & \frac{\partial T_{\text {iono }}^{1}}{\partial \alpha_{3}} & \frac{\partial T_{\text {iono }}^{1}}{\partial \beta_{0}} & \ldots & \frac{\partial T_{\text {iono }}^{1}}{\partial \beta_{3}} \\
\frac{\partial T_{\text {iono }}^{2}}{\partial \alpha_{0}} & \cdots & \frac{\partial T_{\text {ino }}^{2}}{\partial \alpha_{3}} & \frac{\partial T_{\text {iono }}^{2}}{\partial \beta_{0}} & \ldots & \frac{\partial T_{\text {iono }}^{2}}{\partial \beta_{3}} \\
\vdots & & \vdots & \vdots & & \vdots \\
\frac{\partial T_{\text {iono }}^{k}}{\partial \alpha_{0}} & \cdots & \frac{\partial T_{\text {ino }}^{k}}{\partial \alpha_{3}} & \frac{\partial T_{\text {iono }}^{k}}{\partial \beta_{0}} & \cdots & \frac{\partial T_{\text {iono }}^{k}}{\partial \beta_{3}}
\end{array}\right]
$$

Diasumsikan jumlah satelit yang diterima oleh receiver adalah $k$, dan variabel $d$ didefinisikan sebagai $d=\mathrm{T}^{0}{ }_{\text {iono }}-1,546\left(\mathrm{~L}_{1}-\mathrm{L}_{2}\right) / \mathrm{C}$, dimana $\mathrm{C}$ adalah cepat rambat cahaya $\left(\mathrm{C}=3 \times 10^{8} \mathrm{~m} / \mathrm{s}\right)$. Berikut persamaan pengamatan:

$$
[A]\left[\begin{array}{c}
d \alpha_{0} \\
d \alpha_{1} \\
d \alpha_{2} \\
d \alpha_{2} \\
d \beta_{0} \\
d \beta_{1} \\
d \beta_{2} \\
d \beta_{3}
\end{array}\right]+\frac{1,546}{C}\left[\begin{array}{cccc}
1 & 0 & \ldots & 0 \\
0 & 1 & \cdots & 0 \\
\vdots & & 0 & \vdots \\
0 & 0 & \ldots & 1
\end{array}\right]\left[\begin{array}{c}
N 1 \\
N 2 \\
\vdots \\
N k
\end{array}\right]+\left[\begin{array}{c}
d 1 \\
d 2 \\
\vdots \\
d k
\end{array}\right]=\left[\begin{array}{c}
0 \\
0 \\
\vdots \\
0
\end{array}\right]
$$

Selanjutnya dilakukan iterasi pada persaamaan 14 untuk mendapatkan nila d $\alpha$ dan $\mathrm{d} \beta$ mendekati atau sama dengan nol.

\section{Pengolahan RTKLIB}

a. Pengolahan data GPS single frequency Satu set data koefisien Klobuchar dari hasil iterasi dimasukkkan ke file rinex navigasi menggantikan koefisien global.

b. Pengolahan data GPS dual frequency

\section{HASIL DAN PEMBAHASAN}

\section{Hasil Perhitungan Koefisien Klobuchar lokal}

Berdasarkan pengolahan data navigasi dari pengamatan GPS dual frequency selama 24 jam didapatkan nilai sebagai berikut:

Tabel 1. Koefisien Klobuchar lokal

\begin{tabular}{clll}
\hline $\begin{array}{l}\text { Koefisien } \\
\text { Klobuchar }\end{array}$ & $\begin{array}{l}\text { Nilai asli } \\
\text { (semicircle) }\end{array}$ & $\begin{array}{l}\text { Nilai hasil } \\
\text { perhitungan } \\
\text { (semicircle) }\end{array}$ & Selisih \\
\hline $\boldsymbol{\alpha}_{0}$ & 86020,00000 & 86020,05307 & $-0,05307$ \\
\hline $\boldsymbol{\alpha}_{1}$ & 81920,00000 & 81921,22421 & $-1,22421$ \\
$\boldsymbol{\alpha}_{2}$ & $-13110,00000$ & $-131099,85486$ & $-0,14514$ \\
$\boldsymbol{\alpha}_{3}$ & $-52430,00000$ & $-524299,99911$ & $-0,00089$ \\
$\boldsymbol{\beta}_{0}$ & 0,00000 & 0,00213 & $-0,00213$ \\
\hline
\end{tabular}




\begin{tabular}{llll}
\hline & & & \\
\hline $\boldsymbol{\beta}_{1}$ & $-8,88180 \times 10^{-16}$ & $1,17053 \times 10^{-16}$ & $-2,1 \mathrm{E}-15$ \\
$\boldsymbol{\beta}_{2}$ & 589820 & 589823,99999 & $2,48 \mathrm{E}-09$ \\
$\boldsymbol{\beta}_{3}$ & 2001 & 2000,00009 & $-1,9 \mathrm{E}-12$ \\
\hline
\end{tabular}

- Metode 3 : Menggunakan data Single Frequency, dengan koreksi bias ionosfer (Koefisien lokal).

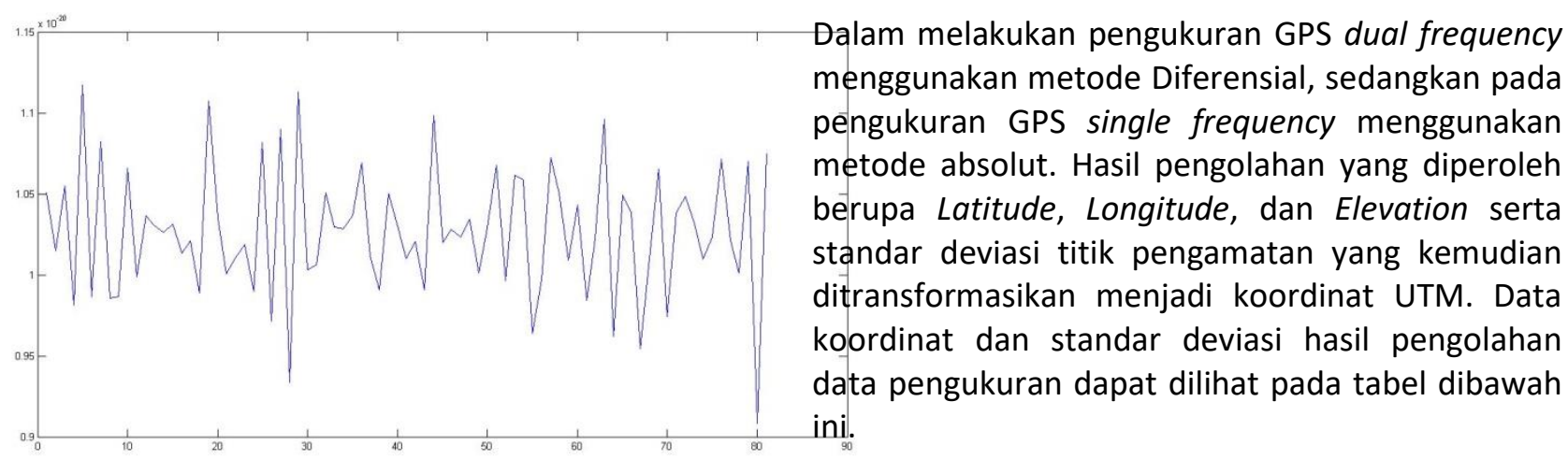

Gambar 2 Grafik perubahan d $\alpha$ dan $d \beta$

Tabel 2. Data Koordinat Geodetik

Sesuai Tabel 1 diatas, dapat dilihat bahwa nilai delta yang didapat sangat kecil, sehingga hasil koefisien yang dihasilkan Tidak berbeda jauh dengan nilai aslinya. Koefisien yang memiliki selisih terbesar adalah koefisien $\beta_{2}$ yaitu 2,48E-09 dan koefisien yang memiliki selisih terkecil adalah koefisien $\alpha_{1}$ yaitu $-1,22421$. Nilai diatas didapatkan melalui proses iterasi sebanyak 89 kali dengan parameter nilai terkecil adalah $10^{-21}$.

Perubahan nilai $d \alpha$ dan $d \beta$ yang tidak teratur disebabkan oleh beberapa faktor, salah satunyadalah faktor lokasi titik pengamatan. Dalaı. penelitian ini lokasi titik pengamatan berdekatan dengan sebuah gedung yang tinggi, sehinggmempengaruhi jumlah satelit yang diterima olel GPS dan dapat menyebabkan kesalaha Multipath.

\section{Hasil Perhitungan Koordinat}

Pengolahan koordinat dilakukan menggunaka perangkat lunak RTKLIB 2.4.2. Terdapat 4 macar metode yang diterapkan dalam pengolahan dat ini, yaitu:

- Metode 1 : Menggunakan data Duc. Frequency, dengan koreksi bias ionosfer (Kombinasi bebas ionosfer).

- Metode 2 : Menggunakan data Single Frequency, tanpa koreksi bias ionosfer.

- Metode 3 : Menggunakan data Single Frequency, dengan koreksi bias ionosfer (Koefisien global).

\begin{tabular}{cccc}
\hline Metode & Lintang & Bujur & Tinggi \\
\hline $\mathbf{1}$ & $-7^{\circ} 16^{\prime} 47,4112^{\prime \prime}$ & $112^{\circ} 47^{\prime} 42,1912^{\prime \prime}$ & $40,22322 \mathrm{~m}$ \\
$\mathbf{2}$ & $-7^{\circ} 16^{\prime} 47,4599^{\prime \prime}$ & $112^{\circ} 47^{\prime} 42,2294^{\prime \prime}$ & $45,65833 \mathrm{~m}$ \\
$\mathbf{3}$ & $-7^{\circ} 16^{\prime} 47,4407^{\prime \prime}$ & $112^{\circ} 47^{\prime} 42,2283^{\prime \prime}$ & $40,48237 \mathrm{~m}$ \\
$\mathbf{4}$ & $-7^{\circ} 16^{\prime} 47,4312^{\prime \prime}$ & $112^{\circ} 47^{\prime} 42,2199^{\prime \prime}$ & $40,42368 \mathrm{~m}$ \\
\hline
\end{tabular}

Tabel 3. Data Koordinat UTM dan Standar Deviasi

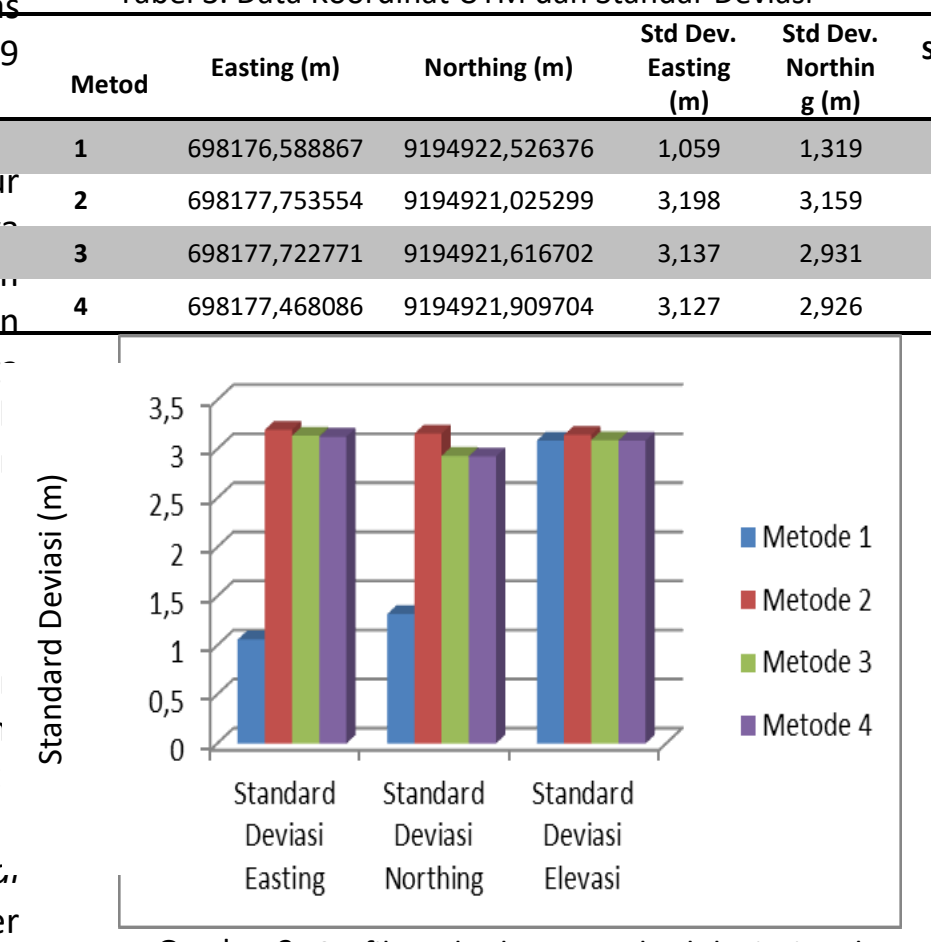

Gambar 3. Grafik perbedaan standard deviasi pada setiap metode pengolahan

Standar deviasi dari masing-masing pengolahan kemudian dibandingkan untuk mengetahui standar deviasi dengan ketelitian yang lebih baik. Berdasarkan grafik 4.4 diketahui bahwa metode 1 menghasilkan data koordinat lebih baik dari 
metode lainnya. Karena metode 1 menggunakan data GPS dual frequency dengan koreksi bias ionosfer (kombinasi bebas ionosfer), selanjutnya data hasil pengolahan metode 1 disebut koordinat yang dianggap benar. Sedangkan untuk data single frequency, metode 4 menghasilkan data koordinat lebih baik daripada metode 2 dan 3.

Analisis perubahan akurasi koordinat hasil pengolahan pada penelitian ini yaitu membandingkan Mean error masing-masing nilai koordinat hasil pengolahan data single frequency terkoreksi bias ionosfer (metode 3 dan 4) terhadap nilai koordinat tanpa koreksi bias ionosfer (metode 2). Mean error adalah rata-rata selisih nilai koordinat metode 2,3 dan 4 terhadap nilai koordinat yang dianggap benar, dimana koordinat yang dianggap benar adalah koordinat hasil pengolahan metode 1 . Perubahan Mean error dapat dilihat pada tabel berikut. frequency. Dimana setiap Mean error nilai koordinat mengalami penurunan, dimana semakin kecil kesalahan maka nilai akan mendekati nilai yang dianggap benar. Perubahan terbesar terjadi pada nilai Elevasi (Z), dengan menggunakan koefisien global perubahan Mean error mencapai 95,232 \% dan menggunakan koefisien lokal sebesar 96,312\%. Perubahan posisi (dr) didapatkan dari persamaan berikut.

$$
d r=\sqrt{\left(X_{a}-X_{b}\right)^{2}+\left(Y_{a}-Y_{b}\right)^{2}+\left(Z_{a}-Z_{b}\right)^{2}}
$$

Dimana posisi $\mathrm{A}\left(X_{\mathbb{E}}, Y_{\mathbb{G}}, Z_{\mathbb{G}}\right)$ adalah posisi koordinat yang dianggap benar dan posisi $\mathrm{B}\left(X_{b}, Y_{b}, Z_{b}\right)$ adalah koordinat hasil metode 2,3 dan 4. Selanjutnya, melakukan analisis perubahan Mean error metode 4 terhadap metode 3 .
Tabel 4. Mean error terhadap metode 1

\begin{tabular}{ccccc}
\hline Metode & \multicolumn{4}{c}{ Mean Error } \\
\cline { 2 - 5 } & Easting & Norhting & Elevasi & $\mathbf{d r}$ \\
$\mathbf{2}$ & $1,165 \mathrm{~m}$ & $1,501 \mathrm{~m}$ & $5,435 \mathrm{~m}$ & $5,757 \mathrm{~m}$ \\
$\mathbf{3}$ & $1,135 \mathrm{~m}$ & $0,910 \mathrm{~m}$ & $0,259 \mathrm{~m}$ & $1,477 \mathrm{~m}$ \\
$\mathbf{4}$ & $1,125 \mathrm{~m}$ & $0,897 \mathrm{~m}$ & $0,201 \mathrm{~m}$ & $1,092 \mathrm{~m}$ \\
\hline
\end{tabular}

Tabel 5. Perubahan Mean error pada Metode 3 tehadap Metode 2

\begin{tabular}{cccc}
\hline Koordinat & \multicolumn{2}{c}{ Mean Error } & $\begin{array}{c}\text { \% perubahan Mea.r. } \\
\text { Error }\end{array}$ \\
\cline { 2 - 3 } Easting & Metode 2 & Metode 3 & Error \\
Northing & $1,165 \mathrm{~m}$ & $1,135 \mathrm{~m}$ & $2,625 \%$ \\
Elevasi & $1,501 \mathrm{~m}$ & $0,910 \mathrm{~m}$ & $39,398 \%$ \\
dr & $5,435 \mathrm{~m}$ & $0,259 \mathrm{~m}$ & $95,232 \%$ \\
\hline
\end{tabular}

Tabel 6. Perubahan Mean error pada Metode 4 tehadap Metode 2

\begin{tabular}{|c|c|c|c|}
\hline \multirow{2}{*}{ Koordinat } & \multicolumn{2}{|c|}{ Mean Error } & \multirow{2}{*}{$\begin{array}{c}\text { \% perubahan Mean } \\
\text { Error }\end{array}$} \\
\hline & Metode 2 & Metode 4 & \\
\hline Easting & $1,165 \mathrm{~m}$ & $1,125 \mathrm{~m}$ & $3,469 \%$ \\
\hline Northing & $1,501 \mathrm{~m}$ & $0,897 \mathrm{~m}$ & $40,254 \%$ \\
\hline Elevasi & $5,435 \mathrm{~m}$ & $0,201 \mathrm{~m}$ & $96,312 \%$ \\
\hline dr & $5,757 \mathrm{~m}$ & $1,092 \mathrm{~m}$ & $81,026 \%$ \\
\hline
\end{tabular}

Berdasarkan tabel 5 dan 6 diketahui bahwa dengan koreksi bias ionosfer akan meningkatkan akurasi koordinat hasil pengamatan GPS single
Tabel 7. Perubahan Mean error pada Metode 4 tehadap Metode 3

\begin{tabular}{|c|c|c|c|}
\hline \multirow{2}{*}{ Koordinat } & \multicolumn{2}{|c|}{ Mean Error } & \multirow{2}{*}{$\begin{array}{c}\% \text { perubahan Mean } \\
\text { Error }\end{array}$} \\
\hline & Metode 2 & Metode 4 & \\
\hline Easting & $1,135 \mathrm{~m}$ & $1,125 \mathrm{~m}$ & $0,867 \%$ \\
\hline Northing & $0,910 \mathrm{~m}$ & $0,897 \mathrm{~m}$ & $1,412 \%$ \\
\hline Elevasi & $0,259 \mathrm{~m}$ & $0,201 \mathrm{~m}$ & $22,646 \%$ \\
\hline$d r$ & $1,477 \mathrm{~m}$ & $1,092 \mathrm{~m}$ & $26,015 \%$ \\
\hline
\end{tabular}

Berdasarkan tabel diatas diketahui bahwa dengan menggunakan metode 4 meningkatkan akurasi pada masing masing nilai koordinat. Perubahan Mean error pada nilai Easting dan Northing tidak terlalu signifikan, karena koefisien Klobuchar yang dihasilkan memiliki selisih yang kecil.

Koefisien Klobuchar berpengaruh terhadap nilai Delay ionosphere, dimana nilai Delay ionosfer mempengaruhi jarak pseudorange dan jarak fase. Secara keseluruhan metode 4 (koreksi ionosfer menggunakan koefisien lokal) menghasilkan kenaikan akurasi lebih baik daripada metode 3 (koreksi ionosfer menggunakan koefisien global). Dengan nilai kenaikan akurasi sebesar $26,015 \%$.

\section{KESIMPULAN}

Berdasarkan hasil penelitian mengenai Koreksi bias ionosfer menggunakan model Klobuchar, maka 
didapatkan beberapa kesimpulan akhir yaitu:

1. Berdasarkan hasil pengolahan koefisien Klobuchar, koefisien yang dihasilkan tidak berbeda jauh dengan nilai awal. Koefisien yang memiliki selisih terbesar adalah koefisien yang memiliki selisih terbesar adalah koefisien $\beta_{2}$ yaitu $2,48 \times 10^{\wedge 9}$ dan koefisien yang memiliki selisih terkecil adalah koefrisien $\alpha_{1}$ yaitu $-1,22421$. Nilai diatas didapatkan melalui proses iterasi sebanyak 89 kali dengan parameter nilai terkecil adalan $10^{-21}$.

2. Dengan menggunakan koreksi bias ionosfer menggunakan koefisien lokal akurasi koordinat meningkat sebesar 26,015\% terhadap penggunaan koefisien global.

\section{UCAPAN TERIMA KASIH}

Penulis R.W.R mengucapkan terima kasih kepada Bapak Mokhamad Nur Cahyadi, ST, MSc. Ph.D dan Bapak Dr. Buldan Muslim, MSc. Selaku dosen pembimbing yang telah banyak membantu dalam penelitian ini sehingga dapat berjalan dengan lancar.

\section{DAFTAR PUSTAKA}

Dutt, Dr VBS., Gowsuddin, S. (2013). "Ionospheric Delay Estimation Using Klobuchar Algorithm for Single Frequency GPS Receivers". International Journal of Advanced Research in Electronics and Communication Engineering 2, 2:201-207.

Klobuchar, J. A. (1987). "Ionospheric time-delay algorithm for single frequency GPS user". IEEE Transactions on Aerospace and Electronic Systems 23, 3:325-331.

Komjathy, A., Wilson, B.D., Runge, T.F., Boulat, B.M., Mannucci, A.J., Sparks, L., Reyes, M.J. (2002). "A New lonospheric Model for Wide Area Differential GPS: The Multiple Shell Approach," Proceedings of the 2002 National Technical Meeting of The Institute of Navigation, San Diego, CA, pp. 460-466

Lee, C.-M., Park, K.-D., Ha, J., Lee, S. (2010). "Generation of Klobuchar Coefficient for Ionospheric Error Simulation". Journal of Astronomy and Space Science 27, 2:117-122.

Yuan Y, Huo X, Ou J, Zhang K, Chai Y. (2008)."Refining the Klobuchar ionospheric coefficients based on GPS observations". IEEE Trans Aerosp Electron Syst, AES-44, 1498-1510. 